\title{
AS MANIFESTAÇÕES DO ATO E SUA SINGULARIDADE EM SUAS RELAÇÕES COM O FEMININO*
}

Cristina Moreira Marcos e Carla de Abreu Machado Derzi

Cristina Moreira Marcos

Psicanalista,

docente do

Programa de

Pós-Graduação em

Psicologia da PUC-

Minas, membro

da Coordenação

do curso de

especialização em

Clínica Psicanalítica

na Atualidade,

doutora em

Psicopatologia

Fundamental e

Psicanálise pela

Universidade de

Paris 7.

Carla de Abreu Machado

Derzi

Psicanalista,

docente do

Programa de

Graduação em

Psicologia da PUC-

Minas, membro

da Coordenação e

professora do curso

de especialização

em Clínica

Psicanalítica na

Atualidade doutora

em Psicanálise pela

Universidade de

Paris 8 .

RESUMO: Pretende-se discutir as possíveis relações entre o ato e o feminino, já que ambos apontam para a manifestação no real daquilo que escapa ao simbólico. Abordam-se as diversas modalidades do ato: passagem ao ato e acting out, saídas encontradas pelos sujeitos diante do mal-estar vivenciado por cada um, assim como a definição lacaniana do ato como uma transgressão de um limite simbólico, para se colocar a questão das relações entre ato e feminino.

Palavras-chave: Ato, feminino, singularidade.

ABSTRACT: The act and its singularities in its relationship with the feminine. The paper is focused on the possible relationships between the act and the feminine, inasmuch as both indicate the manifestation of the real in what is not captured by the symbolic. We consider different categories of act, from the acting out to the different solutions a subject may find to the malaise each one may experience, as well as the lacanian definition of act as a transgression to a symbolic limit, so as to approach the relations between the act and the feminine.

Keywords: Act, feminine, singularity.

\footnotetext{
* Este artigo é parte da pesquisa intitulada "As manifestações do ato e sua singularidade em suas relações com o feminino", financiada pela Fapemg e pela Pró-Reitoria de Pesquisa e Pós-Graduação da PUC Minas.
} 


\section{INTRODUÇÃO}

Pretende-se discutir as possíveis relações entre o ato e o feminino, em suas mais diversas manifestações: a impulsividade, a tentativa de suicídio, a violência, a agressão, o consumo de drogas, as marcas no corpo etc. Tal diversidade se reagrupa, em psicanálise, sob a categoria do ato, pois aponta para a manifestação no real daquilo que escapa ao simbólico. O caso clínico é o que nos permite abordar tais manifestações, não a partir de uma compreensão generalizada do ato, mas a partir do um a um do caso clínico e de sua singularidade. É a partir de cada caso que se pode averiguar o estatuto e a função do ato. Aborda-se assim, suas diversas modalidades: passagem ao ato e acting out, saídas encontradas pelos sujeitos diante do mal-estar vivenciado por cada um, assim como postula a definição lacaniana do ato, que permite afirmar todo ato como uma infração, uma transgressão de um limite simbólico, para se colocar a questão das relações entre ato e feminino. Inicialmente, vão-se abordar as novas modalidades de gozo evidenciadas na atuação e na passagem ao ato em torno da especificidade da clínica na contemporaneidade para, adiante, relacionar o ato com o gozo feminino.

Pode-se levantar a hipótese de que, em nossa época, há uma desordem nos registros do simbólico, do imaginário e do real. O ato ilustra essa desordem, pela manifestação no real em detrimento do simbólico. Provavelmente, isso ocorre devido ao esvanecimento do Outro, do Outro enquanto representante do simbólico, devido ao declínio da função paterna. Há uma descrença no Outro, pois nossa época é marcada por uma descrença na autoridade e por uma descrença no saber. Não há nenhuma instância simbólica que sustente o lugar do Outro, sendo assim, há uma desordem nos registros simbólico, imaginário e real. O desfalecimento do simbólico engendra a manifestação do real e a impregnação do imaginário, pelo fato de que a falta falta.

Antigamente (época moderna), a crença no Outro marcava a presença do Outro sob a forma de enigma e, consequentemente, mostrava a estratégia estabelecida entre o sujeito e o Outro. O Outro podia instituir o enigma, característica que nos mostra que existe alguma coisa no Outro que nos afasta de sua resposta à nossa demanda. A não resposta do Outro promove a crença no Outro, já que essa última instância instaura o enigma e a dúvida. Há um intervalo, uma hiância entre a nossa demanda e a resposta do Outro que institui o desejo. O desejo do Outro presentifica o registro do simbólico, porque nos coloca sempre em equívoco, em dúvida, nos levando crer no Outro, pois a crença é marcada pela dúvida, pelo intervalo, pela falta. O enigma coloca em evidência o significante da falta do Outro. A descrença no Outro aparece exatamente quando a estratégia do sujeito em relação ao Outro fracassa, o Outro não é mais a referência do simbólico, nem marca a falta, assim, a estratégia do sujeito em relação ao Outro deixa de existir. Quando o Outro não é mais colocado em questão, em enigma, 
surge a descrença. A descrença no Outro é o índice do afastamento e da separação do sujeito em relação ao Outro. O desfalecimento do Outro é confrontado com a predominância de uma clínica do real.

A atuação e a passagem ao ato, nesse contexto contemporâneo, parecem ilustrar a clínica do real, a partir da transgressão do código simbólico. Retomando a teoria freudiana, aquilo que não se recorda reaparece sob repetição, sob atuação. Ou ainda, aquilo que não é representável, se mostra. A clínica do real refere-se ao impossível de dizer do sujeito, que se exibe em um peculiar modo de apresentação na clínica, no qual a dimensão do ato é determinante. O ato exclui a dimensão discursiva e se resume em uma ação separada da ordem significante. Nas manifestações clínicas nas quais imperam o ato, o sujeito permanece entre parênteses. A encenação, a atuação, a mostração, tomam o lugar da palavra, do dizer. Parece haver assim um estreitamento do registro simbólico que se manifesta em um estreitamento do campo do discurso nos levando a falar em uma clínica do real, definido como impossível (LACAN, 1964/1975). O ato é aquilo que se apresenta diante do indizível do significante, diante do impossível de articular ao nível do significante, impõe-se o ato.

O remanejo constante do DSM (Diagnostic and Stastical Manual of Mental Disorders) na medicina elucida ainda mais as mudanças nas manifestações clínicas diante desse novo contexto. O DSM altera incessantemente as classificações das doenças mentais, porque pretende abordar o inapreensível, pretende codificar o não codificável, pretende eliminar o real. As manifestações clínicas atuais apontam uma clínica do real, assim sendo, o número dos inclassificáveis aumenta, já que o real nos remete obrigatoriamente à singularidade de cada caso, como ilustra o gozo feminino.

São manifestações clínicas cada vez mais frequentes na atualidade: a depressão ${ }^{1}$, o transtorno do pânico, a hiperatividade, a anorexia, a bulimia, a atuação, a passagem ao ato, a toxicomania, entre outros; surgem novos modos de gozo na cena contemporânea, os quais levam o psicanalista a responder seja no âmbito particular, seja no âmbito público. A psicanálise é de fundamental importância a partir do momento que leva em consideração a articulação entre o real e a linguagem. Esse é o nosso ponto de partida. É exatamente pelo fato de o encontro entre o singular (sujeito) e o coletivo (civilização) não seguirem uma padronização, que a psicanálise propõe tratar os impasses de cada sujeito como efeito da civilização. Na psicanálise, o universal é concebido a partir das particularidades dos casos clínicos.

\footnotetext{
${ }^{1}$ A depressão ocorre em maior incidência nas mulheres, sendo que $60 \%$ de pessoas que cometem suicídio apresentam sintomas característicos dessa doença (VARELLA, 2006). É importante ressaltar o suicídio (passagem ao ato) e a incidência da depressão em mulheres.
} 
A angústia, por exemplo, aumenta em nossos dias, ilustrando a ruína do Outro e testemunhando as manifestações do real. Freud traz contribuições à clínica da angústia desde 1894, a partir de sua teoria sobre a neurose de angústia. Essa é a razão pela qual há o crescimento do número de pessoas que sofrem de transtorno do pânico. Esse aumento considerável de casos foi o que permitiu que essa doença (transtorno do pânico) tenha sido inserida no CID (Código Internacional de Doenças) na década de 1980.

A angústia indica que resta apenas um último ponto a atravessar para aceder à ausência do Outro, ou seja, embora exista ainda uma experiência do Outro, a presença do Outro como desejo do Outro não está em causa. A angústia é a clínica na qual a falta falta. A angústia não é a falta, mas o desaparecimento da falta. Sendo assim, essa é a razão pela qual Lacan afirma "a angustia é o afeto que não engana” (LACAN, 1962-1963/2005), pois estamos diante da certeza, da clínica do real. Ao contrário dessa clínica, o desejo situado no registro do simbólico, marca e existência da falta, da falta de certeza, o que nos possibilita crer. A angústia não é sem objeto, é a presença do objeto a, esse a não assimilável pelo significante, fazendo aparecer um limite na linguagem. A angústia denuncia que existe um desejo soterrado, esmagado pela presença do objeto a. Se a angústia é um afeto que não engana, porque ela é consequência de um gozo não “significantizável”, ela advém da ordem do real.

O aumento do número de atuações e da clínica da angústia está inter-relacionado pelo fato de que as atuações evitam e revelam a angústia. A atuação isola a angústia da certeza, sendo uma forma de interromper a espera, permitindo ao sujeito sair da situação angustiante. A angústia mostra a falta de uma elaboração subjetiva conveniente, mostra a falta de uma elaboração simbólica desse afeto, o que leva o sujeito ao ato. A atuação torna-se uma maneira de evitar a angústia.

As atuações são repetições sob a pressão de uma compulsão. Freud (1920/1989) admite a existência de uma compulsão à repetição na história de homens e mulheres, sendo que a compulsão à repetição tem um caráter pulsional; a pulsão é exatamente a força que sustenta a repetição. Freud atribui a compulsão à repetição como sendo uma força demoníaca do destino. Lacan (1964/1975) articula essa repetição pela vertente do real, como "ponto ideal fora do traçado", nomeado por ele de gozo. As atuações não ocorrem restritamente de forma casual, ela revela que o sujeito não pode deixar de experimentar as mesmas coisas, mesmo que seja a partir do acidental ou do acaso. É frequente assim, as atuações apresentarem-se sob forma de repetição, ou melhor, sob forma de seriação, posto que há um núcleo inassimilável que persevera e que não pode ser (pre)visto. Trata-se, então, de considerar nas manifestações do ato, certa impossibilidade de responder ao enigma pulsional. 
A pergunta acerca do ato e de sua incidência nas mulheres justifica-se na medida em que o gozo feminino nos remete obrigatoriamente ao indizível, ao real. Embora o gozo feminino não acompanhe a anatomia do corpo, as mulheres se aproximam de um modo privilegiado do real. Sendo assim, não se trata de estudar as relações entre o gênero (mulher) e o ato, mas a relação entre o ato e o gozo feminino. Além disso, as estatísticas médicas revelam que o transtorno do pânico é mais frequente em mulheres do que em homens (NARDI, 2005). Assim sendo, trata-se de ir além da linguagem, reconhecendo o limite da interpretação, afinal essa clínica situa-se na estrutura do não-todo, diferentemente de tempos atrás, quando a estrutura era sustentada pela função paterna, caracterizada pelo todo, porque a presença da exceção permitia a constituição do todo. Portanto, deve-se levar em consideração o gozo feminino, pois é ele que presentifica o real em jogo e ilustra a contingência inerente ao nosso mundo atual: o não-todo.

A presentificação do real, na clínica atual, se esclarece através da diferença com a clínica do todo, da sexuação masculina e do campo fálico. Assim sendo, a clínica nos obriga a passar da representação à presentificação. A presentificação, ou melhor, o tornar presente o objeto, denuncia a impossibilidade da substituição, na qual o simbólico se encontra arruinado, desertado (MELMAN, 2003). A representação à época moderna é da ordem da estrutura que se caracteriza pela mudança de posições de elementos graças à possibilidade de circulação entre eles. A falta encontra-se inscrita e circunscrita no simbólico, pois a circulação entre os elementos ocorre devido à presença da falta. A presentificação é da ordem do irrepresentável, ela está além do universo da linguagem, onde a falta falta e o vazio se presentifica. O objeto se apresenta como um vazio encarnado, escancarado. O mundo simbólico cede lugar para a manifestação do real. O mundo pós-moderno promove a saída dos modos de lidar com o simbólico, a saída dos modos de abordar a falta e a castração e alcança a clínica do real.

O sujeito se apresenta não querendo saber o sentido, o recalcado, o escondido. Ele se apresenta pela atuação, desprovida de sentido. Em outras palavras, o sujeito exterioriza através do ato o que não foi demonstrado pela articulação simbólica, trata-se de uma mostração, ou ainda, uma monstração (WAJCMAN, 1998). Como tratar a clínica da atualidade, já que nos aponta que o real insiste em denunciar uma impossibilidade no tratamento? O que oferecer diante dessas proliferações clínicas que se manifestam na ordem do real sem amaragem da ordem fálica?

\section{O ATO A PARTIR DA PSICANÁLISE}

A expressão 'passagem ao ato’ designa, em psiquiatria, atos impulsivos, violentos, infratores, como assassinatos, suicídios e atentados sexuais. Esse fenômeno clínico é descrito como impulsivo e agressivo e, frequentemente, é utilizado 
para designar comportamentos criminosos, delinquentes e psicóticos. O termo serve assim para sublinhar a violência e a impulsividade de diversas condutas que parecem produzir um curto-circuito na vida mental do sujeito precipitando-o em uma ação: uma agressão, um comportamento perverso, um delito.

Em Freud (1914/1989), o termo agieren aparece em seu artigo "Recordar, repetir e elaborar" para definir a repetição em ato que viria no lugar da recordação. O objetivo primordial do tratamento é restabelecer o material que foi esquecido devido ao recalque. São lacunas que devem ser preenchidas pela rememoração, entretanto, a rememoração nem sempre é possível e bem sucedida. O paciente coloca então em ato o que não faz surgir pela via da rememoração. O setting analítico mostra essas atuações, já que nem sempre o sujeito é representado pelo significante: silêncios, ausências, choros e interrupções são constantes nas sessões analíticas. O umbigo do sonho, falado por Freud na teoria dos sonhos, esclarece que um elemento do sonho não encontra palavra, o sonhador não sabe o que dizer a respeito desse caroço no sonho, pois esse caroço não remete a nenhum significante. Além do setting analítico, as pichações frequentes, o uso dos piercings e tatuagens, a fuga das escolas, a agressividade, até o consumo desenfreado de drogas, os acidentes graves e a violência podem ser considerados atuações. O termo 'ato' foi traduzido em inglês como acting out. O espectro de atos que se classificou sob a denominação de acting out tornou-se bastante amplo, incluindo assim o que a clínica psiquiátrica chama de 'passagem ao ato'. Essa extensão coloca o problema da delimitação do conceito, relativamente vago e variado segundo os autores, em relação a outros conceitos freudianos. Sônia Alberti (1999) fez uma análise detalhada e rigorosa do termo 'ato' na obra freudiana, buscando elucidar sua multiplicidade. Desse estudo destacam-se os termos: Aktion, Handlung, Akt, Tat e Agieren.

Aktion aparece na obra de Freud referindo-se à ação específica que implica a realização de mudanças no mundo exterior a serem desempenhadas pelo aparelho psíquico, diante das estimulações vindas do interior do corpo e que perturbam a homeostase. Ela está a serviço do princípio do prazer, visando conservar a energia em um mínimo ideal. A ação específica está articulada ao desamparo fundamental do bebê e ao aparecimento do princípio de realidade. Trata-se de escapar das excitações oriundas do próprio organismo, por meio do princípio de realidade que consiste em um reconhecimento do mundo exterior, o qual o bebê buscará transformar de acordo com suas necessidades.

Handlung é a ação específica desenvolvida a partir da distinção entre necessidade e desejo. O princípio de realidade permitirá o teste por meio do qual o aparelho psíquico adaptará a realidade ao seu desejo. O modelo energético é o mesmo da ação específica, mas exige muito mais energia na medida em que sua ação é mais complexa. Para chegar à Handlung, é preciso primeiro acumular a 
energia para que, em um segundo momento, ela possa se dirigir a um objetivo, contrariando assim o princípio de prazer.

O termo Akt está em relação explícita com o ato sexual, o coito. Em seu artigo “Para além do princípio do prazer”, Freud (1920/1989) aponta que o ato sexual é o que põe o sujeito em relação com seu gozo, no qual o homem atinge o maior prazer do qual é capaz. Em 1920, Freud também utiliza esse termo para falar do fort-da, assinalando que, no ato, trata-se de repetição. Ainda nesse texto, Freud trata do Akt preparatório.

O termo Tat é utilizado pelo psicanalista para designar o assassinato do pai primevo em “Totem e tabu”. O homem primitivo estaria no registro do Tat, visto que não sofreu as renúncias pulsionais do homem da cultura. Por isso, o Tat não se encontra sobre a cena do desejo inconsciente, mas sobre a cena da realidade. Trata-se de um ato que não deveria ser repetido, por isto não o encontramos no neurótico Taten, mas ‘inibição’.

Brodsky (2004) afirma que há duas portas de entrada para se estudar o ato em Freud. A primeira delas está no começo do seu ensino, em A psicopatologia da vida cotidiana (1901/1989). Nesse escrito, o ato é considerado como uma dentre outras formações do inconsciente. Podemos dizer que o ato surge na psicanálise como ato falho ou ato sintomático. Temos, nesse texto de 1901, uma grande classificação dos atos. Os atos são aí definidos como portadores de uma significação e, portanto, perdem a inocência com a qual eram caracterizados. Eles não são meras ações, eles possuem um sentido. A outra porta de entrada, apontada por Brodsky, é o texto "Recordar, repetir e elaborar” (1914/1989). Nesse artigo, Freud aborda o ato de outro lugar, definindo-o como o que se opõe à recordação. O ato aqui não é trabalhado como ato interpretável, mas como ato que se opõe à rememoração que desembocaria na interpretação. Por isso, Brodsky afirma que o ato fica, nesse texto, situado como algo contrário à lógica do inconsciente, pois o inconsciente se repete de um modo e o ato, de outro. Nestas duas perspectivas, "A psicopatologia da vida cotidiana” e "Recordar, repetir e elaborar" temos, respectivamente, o ato como interpretável e o ato como o que se opõe ao inconsciente

É, sobretudo, em O Seminário, Livro 10: A angústia (1962-1963/2005) que Lacan torna possível a distinção entre passagem ao ato e acting out, a partir do comentário do caso da jovem homossexual e do caso Dora. Entretanto, o tema do ato já o interessava desde muito antes, a partir do estudo sobre o crime das irmãs Papin, no qual o ato criminoso aparece como uma solução para o "delírio a dois" e na tese sobre o caso Aimée, no qual a passagem ao ato tem uma função de remissão do delírio.

Se inicialmente Lacan trabalha com a concepção psiquiátrica da passagem ao ato, a partir de 1962 ele começa a formalizar o conceito do ato partindo de 
uma perspectiva psicanalítica. Isto leva a uma precisão conceitual que nos permite a disjunção desse fenômeno clínico com um tipo específico de estrutura: a psicose.

Em A direção da cura e os princípios de seu poder (1958/1966), o acting out é analisado a partir do caso do "Homem dos miolos frescos", atendido por Ernest Kris. O acting out aparece como uma resposta do analisante à interpretação equivocada do analista. Em 1962, no citado Seminário A angústia, Lacan distingue 'passagem ao ato’ e acting out, a partir da angústia e do objeto a. Em O Seminário, Livro 15: O ato analítico (1976-8), Lacan teoriza acerca da clínica do ato e elabora o conceito de 'ato verdadeiro'.

No Seminário X, a passagem ao ato e o acting out serão abordados a partir da angústia e do objeto a, como correlato subjetivo da angústia. Essas duas modalidades do ato indicam operações por meio das quais o sujeito se relaciona com o objeto a. Para delimitar e definir estes dois modos de agir, Lacan nos remete aos casos “Dora” (FREUD, 1905/1989) e “A jovem homossexual” (FREUD, 1920a/1989).

O quarteto amoroso vivido entre Dora, seu pai, o sr. K. e a sra. K. implica, segundo Lacan, em um acting out. Há ali a montagem de uma cena na qual fica evidente a mostração e a provocação diante do olhar do Outro. A amizade de Dora e de seu pai pelo casal encobre uma trama complexa de relações. A sra. K cuidou do pai de Dora durante o período em que ele esteve doente e mantém com ele um caso amoroso embora ele seja impotente. Dora encontra-se assim oferecida aos galanteios do sr. K., que sempre lhe foi muito amável, trazendolhe presentes e a convidou a passear. Nessa história, cada um se faz cúmplice do outro: o pai fecha os olhos, Dora encobre as relações de seu pai com a sra. K.

O momento crucial é aquele em que o sr. K aborda Dora à beira do lago e lhe faz uma declaração de amor dizendo-lhe que sua mulher não era nada para ele. Sua resposta é uma bofetada. A partir daí, a harmonia do quarteto se desfaz. Dora vai se mostrar insuportável, chegando a ameaçar suicídio. É assim que ela chega à Freud. Ela marca a passagem ao ato, depois do acting out. A passagem ao ato implica uma retirada da cena, um corte no qual a história dá um giro. Se o acting out se sustenta por muito tempo na sedução endereçada ao sr. K., esta encenação se desfaz na cena do lago, na qual, após a revelação do sr. K. de que a sra. K. não era nada para ele, Dora se vê reduzida à nada. Sua única saída é se subtrair à cena.

No caso da jovem homossexual, Lacan se refere ao abandono da cena efetuado pela jovem de modo bastante espetacular, caracterizando a passagem ao ato. A jovem havia se interessado por uma dama mais velha, de reputação duvidosa, descrita como uma cocotte. Ela lhe dirige um amor do tipo cortês, cavalheiresco, oferecendo-lhe flores e devoção. O desafio implicado nesta relação era acentuado 
por passeios ostensivos na companhia da dama pelas proximidades do local de trabalho de seu pai. Todo esse movimento em torno desta mulher configurava um acting out, montando uma cena e sua exibição. O caso amoroso da jovem homossexual com a dama não é mais que um acting out endereçado ao Outro paterno.

Lacan (1962-1963/2005) afirma que a orientação para o Outro deve ser destacada no acting out. Ele é algo que se mostra na conduta do sujeito. No caso Dora, todo o seu comportamento ambíguo com o sr. K. e, no caso da jovem homossexual, toda a sua aventura com a dama, são acting out. Há uma tentativa de manter o objeto a a certa distância. Assim como a fantasia é uma barreira contra a angústia, o acting out constrói uma encenação ficcional do objeto a. Entretanto, nele, algo da fantasia é atuado. O acting out é uma figura de encenação, uma exteriorização pela via do ato, ele mostra pelo ato aquilo que não foi demonstrado pela via simbólica. A presença da encenação no acting out indica não apenas a presença do Outro, mas também o endereçamento ao Outro. Sendo assim, o acting out é um fenômeno vinculado à dialética do inconsciente.

Um belo dia, o pai cruza com a filha em um de seus passeios na companhia da dama cortejada. O pai lança um olhar enfurecido à filha e a dama lhe pergunta então quem era aquele senhor. Sabendo que se tratava do pai da jovem, a dama lhe propõe interromperem seus encontros. Neste instante, a jovem joga-se da ponte caindo na linha de trem que passava embaixo. Identificada com o objeto a (olhar), a jovem segue o destino do objeto que é separar, cair. Na tentativa de suicídio a jovem se deixa cair. O resultado da passagem ao ato é a queda, pela qual o a, ocupa o lugar de dejeto.

Freud busca compreender a tentativa de suicídio da jovem a partir do equívoco significante presente no verbo niederkommen (cair, parir). Porém a passagem ao ato subtrai o sujeito do registro do simbólico para situá-lo no lugar do real. O sujeito deixa de ser um significante que se representa para outro significante, para ser aquilo que escapa à simbolização, identificando-se ao objeto a. A passagem ao ato indica o rechaço do inconsciente, pois temos uma ruptura radical, um rasgo na linguagem, ocorrendo a desaparição do cenário e do espectador, apontando algo que ultrapassa o sujeito.

Dora identifica-se ao nada assim como a jovem homossexual identifica-se ao olhar enfurecido do pai. O nada e o olhar são as duas formas do objeto que surgem em ambos os casos. Diante da angústia que surge, Lacan afirma que o sujeito encontra-se embaraçado. Ele está fora de toda representação possível.

A bofetada de Dora no sr. K. e a tentativa de suicídio da jovem homossexual permitem, numa relação quase direta com o objeto a, evitar transitoriamente a angústia. Ambos os casos demonstram que existe uma relação estrutural entre a passagem ao ato e ao objeto $a$, na medida em que se manifestam sob a forma de 
um Niederkommen, do "deixar cair" como dejeto. Do lado da cena que determina o sujeito, dali onde ele está, ele se precipita e cai. A cena que faz despencar é a própria vacilação da fantasia, barreira ao objeto a. Há uma identificação absoluta com o objeto a, ao qual o sujeito se reduz. Ele é assim expulso da cena e cai. A identificação ao objeto a mostra a falência do Outro, ilustrando a falta de recurso simbólico e a manifestação do real.

A bofetada de Dora faz com que todos a considerem doente e a harmonia do quarteto se rompe. Essa saída da cena, que vemos em Dora, é a própria estrutura da passagem ao ato. Se a mulher do sr. K. não era nada para ele, o que era Dora para o sr. K.? Nada. A tentativa de suicídio da jovem homossexual segue a mesma estrutura. Reduzida a nada, ela pula da ponte. O ato é uma saída da determinação simbólica, um furo na ordem simbólica, mesmo sabendo que para que haja passagem ao ato é preciso que haja anteriormente uma inscrição simbólica.

Em Seminário XV: $O$ ato analítico, Lacan afirma que toda ação tem uma ponta significante e é isto que define o ato. As coordenadas do ato são simbólicas. Para o psicanalista “ $[\mathrm{n}]$ o começo era a ação, porque sem ato não poderia, muito simplesmente, ser questão de começo. A ação está exatamente no começo, porque não poderia haver começo sem ação” (LACAN, 1967-1968/1987). Não existe ação sem verbo, sem uma ponta significante.

Sabemos que o exemplo dado por Lacan do que seria um ato é o momento em que César atravessa o Rubicão. Brodsky, comentando esta escolha de Lacan, lembra que o rio Rubicão é um fiapo de água, para ultrapassá-lo basta um passo, um salto. Entretanto, ele representa uma fronteira, um limite que não podia ser ultrapassado pelo exército da República. Tendo passado para o outro lado do Rubicão, César desafia as leis da República, indo além das coordenadas simbólicas que regiam as leis da época. De soldado, César passa a rebelde, ao ultrapassar o Rubicão. Lacan dá esse exemplo para demonstrar que um ato se define por suas coordenadas simbólicas e não pela ação. Há um corte que instala um antes e um depois, um atravessamento de um limite no qual o sujeito se coloca como fora da lei.

\footnotetext{
“Todo ato verdadeiro é delinquente, observamos isto na história, que não há ato verdadeiro que não comporte um atravessamento de um código, de uma lei, de um conjunto simbólico, com o qual, pouco ou muito, constitui-se como infrator, o que permite a este ato ter oportunidade de reorganizar essa codificação.” (MILLER, 1993, p.45)
}

Entretanto, a presença do ato não deve ser pensada apenas na vertente do afrontamento à lei da justiça. Para a Psicanálise, não se trata da lei que serve à justiça, trata-se de lei do desejo, que corresponde a uma crise de revolta com o 
Outro da lei, e também corresponde à possibilidade de "sair de cena”, constituindo como uma resposta ao impossível de suportar. Na psicanálise, a lei do desejo está fundada no Nome-do-Pai, enquanto ponto de basta de algumas respostas, que impedem que o sujeito fique tão à deriva. A lei delegada ao Nome-do-Pai, leva em conta a singularidade, já que vai ao encontro do sujeito e sua invenção. Cada sujeito é único, fazendo seus arranjos conforme sua posição singular frente à castração. Enfim, no presente trabalho o ato adota a dimensão de ser uma transgressão, pelo fato de transgredir um conjunto simbólico, não se servindo assim, à lei da justiça.

$\mathrm{O}$ ato de César constitui uma ultrapassagem de um limiar no qual o sujeito se coloca como fora da lei. Se, como afirma Lacan, todo ato verdadeiro é um “suicídio do sujeito”, ele morre e renasce no ato, mas o sujeito não é o mesmo de antes. Por isso, pode-se tratar no ato de uma tentativa de inscrição do sujeito. O apelo ao Outro na atuação, mostra que o aumento das atuações em nossa época denuncia a descrença no Outro em nossos dias atuais. O sujeito pode atuar numa tentativa em crer no Outro. Esse apelo ilustra a necessidade de existir uma estratégia entre o sujeito e o Outro, ilustrando assim uma tentativa de inscrição do sujeito no Outro.

O fora da lei remete a um gozo que não foi coordenado pelo falo, ou melhor, a estrutura da linguagem, pelo fato de ser constituída a partir da falta de um significante, aponta para um impossível de ser significantizado: um "fora da lei”. Lacan aponta este "fora da lei" de diversos modos: "a relação sexual não existe”, "não existe a metalinguagem”, “a inexistência do significante feminino”, "o Outro sexo" etc.

\section{O ATO NO FEMININO E SUA SINGULARIDADE}

Se todo ato verdadeiro é delinquente, é um furo na ordem simbólica, trata-se de investigar as modalidades do ato em sua singularidade e suas relações com o feminino. Lacan aborda a questão da sexualidade feminina a partir da diferenciação entre o gozo fálico e o gozo suplementar. Em relação à identidade feminina, Lacan retoma o princípio freudiano do primado do falo como o representante da diferença entre os sexos no inconsciente através da postulação da inexistência de um significante d’A mulher. Quanto ao Édipo, ele afirma que as mulheres são não-todas inscritas na função fálica, assinalando um além do Édipo e um além da castração. Ao mesmo tempo em que elas estão submetidas ao Édipo e à castração, elas deles escapam. Finalmente, quanto à sexualidade, ele coloca uma ênfase menos sobre uma mudança de sexo (do masculino para o feminino) e de objeto (do clitóris para a vagina) do que sobre um suplemento que viria se acrescentar ao gozo fálico. 
Lacan não faz objeção ao falocentrismo freudiano, ele extrai do Édipo a lógica de conjunto do todo. Em sua leitura, o Édipo é reduzido à lógica única da castração e a isso se acrescenta o fato de que esta lógica não regula todo o campo do gozo. Há uma parte que não é regulada pelo falo e permanece real. Dizer que as mulheres são não-todas na função fálica é reconhecer outro gozo que não aquele limitado pela castração. Neste sentido, Lacan formaliza o além do Édipo com a lógica do não-todo. Ele afirma o falocentrismo do inconsciente "com base em fatos clínicos” (LACAN, 1958a/1966, p. 686). O significante fálico é o significante-mestre da relação entre os sexos. Ele é o padrão, a medida comum, que organiza a diferença entre homens e mulheres. Entretanto o outro gozo, que se acrescenta ao fálico, só pode ser situável a partir de outra lógica: a lógica do não-todo. Esta formalização de Lacan nos leva à construção de uma clínica do real. Quais seriam suas manifestações? Ele as afirma esporádicas, contingentes, em oposição à constância da função fálica para todo homem.

É através da teorização do não-todo que Lacan tentará formalizar a particularidade da relação ao falo e ao real na mulher. A noção do não-todo é um modo de pensar esta relação como uma irrupção do real na mulher que não é inteiramente tributária da castração. Parece-nos que Lacan tenta responder à questão do feminino menos pelo falo/castração que pela distinção entre os dois gozos. A hipótese segundo a qual haveria algo de suplementar ao falo na mulher, algo de irredutível ao falo, é outro modo de leitura da relação privilegiada das mulheres com o real. É este desdobramento do sujeito feminino que Lacan vai formalizar melhor no seminário Mais, ainda (1975/1972-1973).

"Como conceber que o Outro possa ser em algum lugar aquilo em relação a quê uma metade - porque também é grosseiramente a proporção biológica — uma metade dos seres falantes se refere? É, entretanto, o que está escrito lá no quadro com aquela flecha partindo do $\mathbb{A}$. Esse $\mathbb{A}$ não se pode dizer. Nada se pode dizer da mulher. A mulher tem relação com $\$($ de $\mathbb{A}$ ), e já é nisso que ela se duplica, que ela não é toda, pois, por outro lado, ela pode ter relação com o falo." (LACAN, 1975/1972-1973, p. 75) [Tradução nossa].

O feminino é considerado, por Lacan, a partir da tese de um ser que não se submete inteiramente ao Édipo e à lei da castração. Privilegiando menos a identidade do que o gozo feminino, menos a castração e a inveja do pênis do que a divisão introduzida na menina pelo primado do falo, ele funda suas interrogações a propósito do feminino na divisão da mulher entre os dois gozos.

Na teoria lacaniana, o falo e a castração não se colocam mais como obstáculo à feminilidade, mas como suas condições. Para abrir as portas ao tornar-se mulher, Freud se apoia sobre a divergência das consequências do complexo de 
castração no menino e na menina. Lacan, por sua vez, afirma que a menina não disporia somente da referência à castração para tornar-se mulher. Observa-se ainda, que Lacan ressalta que o complexo de Édipo feminino em Freud se encontra confuso, variável, contraditório e enigmático pelo fato de o feminino não se enquadrar na castração.

É porque uma mulher não está completamente submetida à lei da palavra, e ao gozo que daí resulta, que haveria uma possibilidade de outro gozo não-todo referido ao falo. As mulheres não formam um conjunto, não existe uma maneira de ser mulher; existem múltiplas reações respectivas frente à castração. Resta um inominável, um real que goza de outro gozo, suplementar ao falo. Esse gozo suplementar não obedece a nenhuma classificação, não obedece ao universal, mostrando infinitas singularidades. A divisão não é feita entre a vagina e o clitóris ou entre a atividade e a passividade, mas segundo a divisão que separa a linguagem e o corpo, o real e o simbólico. A mulher, não inteiramente submetida ao simbólico, teria uma relação privilegiada com o real.

É preciso considerar o real da clínica, enquanto o impossível de suportar. A passagem ao ato seria um modo de manifestação desta proximidade com o real? A passagem ao ato se aproxima ao gozo feminino pelo fato de apontar um gozo sem medida? Ou ainda, a passagem ao ato se aproxima ao gozo feminino pelo fato de ambos remeterem a uma singularidade? A tese da primazia do falo de Freud foi extremamente importante, embora Lacan tenha reconhecido o limite da função fálica, operando a partir de sua positividade, ele nunca renunciou dela. Sendo assim, não podemos pensar no gozo feminino a partir da eliminação do gozo fálico.

Será que o acting out e a passagem ao ato seriam um modo da manifestação do gozo feminino, ou seria um modo de manifestação que se aproxima ao gozo fálico? Qual a diferença entre o acting out e a passagem ao ato a partir da relação entre o gozo fálico e o gozo feminino? Talvez o gozo feminino e a necessária inclusão do gozo fálico contribuam para melhor precisar as atuações e as passagens ao ato na clínica, evidenciando suas diferenças para um esclarecimento e aprofundamento desses conceitos.

Lacan confere à lógica do não-todo o nome de 'gozo feminino' que pode ser localizado, por exemplo, no campo do amor em uma vertente mística do amor (LACAN, 1975/1972-1973). Este gozo se revelaria também em certos atos que testemunham uma lógica outra que a lógica fálica da falta a ter e da falta a ser, embora não se possa dizer que todo ato seja tributário desta lógica outra. Podemos encontrar um exemplo desses atos no assassinato de Medeia mencionado por Lacan (1958b/1966). A oposição entre estas duas lógicas do gozo fálico e do gozo feminino abre uma perspectiva interessante de estudo do ato. 
Conhecemos a história de Medeia na mitologia grega. Essa mulher que, pelo amor de um homem, Jason, mata seu pai, provavelmente seu irmão, vai-se colocando a serviço do amante. Em uma de suas viagens, Jason, entretanto, enamorase da filha do rei e, pretendendo desposá-la, abandona Medeia. A resposta de Medeia será matar seus próprios filhos. Sua vingança consiste em eliminar os filhos de Jason, atingindo-o naquilo que faz dele um homem a partir de uma descendência, inscrevendo-o em uma cadeia simbólica de filiação, a partir do nome, a partir do nome do pai. Matando seus dois filhos, ela abala a ordem simbólica. Quando Jason lhe pede os corpos dos filhos, para que ele pudesse enterrá-los e escrever seu nome em uma lápide, ela se recusa a entregar-lhe. Podemos dizer que Medeia atinge, desse modo, o nome de Jason, no que tange àquilo que o inscreve em uma ordem simbólica, que o sucede, que perpetua sua existência.

Lacan aponta Medeia como exemplo de um ato feminino deixando entrever uma outra lógica diferente da lógica simbólica, que rege as leis de parentesco e as leis da linguagem. Esse exemplo parece dissociar uma lógica que inscreve Medeia nas leis do pai e da transmissão e uma lógica de outra ordem. É porque ama Jason que ela se vinga dessa forma. Sabemos que a perspectiva aberta por Lacan é definir o feminino não somente a partir do funcionamento edipiano e simbólico, embora também a partir dele. A teoria ensina que há uma relação privilegiada das mulheres com o real, entretanto não se trata de tomar esta premissa como uma orientação geral, mas de investigar, em cada caso, as possíveis manifestações deste real.

Recebido em 11/10/2010. Aprovado em 1/3/2011.

\section{REFERÊNCIĀS}

ALBERTI, S. (1999) Esse sujeito adolescente. Rio de Janeiro: Rios Ambiciosos.

ALVES, E. e VASCONCELOS, F. (2008) Prevalência de sintomas de anorexia nervosa e insatisfação com a imagem corporal em adolescentes do sexo feminino do município de Florianópolis, Santa Catarina, Brasil. Cad. Saúde Pública, v.24, n.3, Rio de Janeiro, p.3-15.

BARRETO, C. e BRANDÃO, M. (Org.). (2008) Liberdade assistida: uma medida. Secretaria Municipal Adjunta de Assistência Social da Prefeitura Municipal de Belo Horizonte.

BRODSKY, G. (2004) Short story: Os princípios do ato analítico. Rio de Janeiro: Contra Capa. 
DUTRA, M.C.B. (1999) "As relações entre psicose e periculosidade: contribuições clínicas da concepção psicanalítica da passagem ao ato”. Dissertação de Mestrado, Programa de Pós-Graduação em Psicologia, Faculdade de Filosofia e Ciências Humanas, Universidade Federal de Minas Gerais.

FREUD, S. (1894/2005) Du bien-fondé à separer de la neurasthenia um complexe de symptômes determine, en tant que "névrose d'angoisse". Paris: PUF.

FREUD, S. (1989) Edição standard brasileira das obras psicológicas completas de Sigmund Freud. Rio de Janeiro: Imago.

(1901) “A psicopatologia da vida cotidiana", v.VI.

(1905) "Fragmento de uma análise de um caso de histeria”, v.VII, p.1-119.

(1914) “Recordar, repetir e elaborar”, v.XII, p.191-203.

(1920) "Além do princípio do prazer", v.XVIII, p.13-85.

(1920a) "A psicogênese de um caso de homossexualismo numa mulher", v.XVIII, p.183-212.

GARCIA, C. (2004) Psicologia jurídica: operadores do simbólico. Belo Horizonte: Del Rei.

LACAN, J. (1966) Écrits. Paris: Seuil.

(1958) "La direction de la cure et les principes de son pouvoir".

(1958a) "La signification du phallus".

(1958b) "Jeunesse de Gide ou la lettre et le désir".

(1960). “Subversion du sujet et dialectique du désir dans l'inconscient freudien".

(1962-1963/2005) O Seminário Livro 10, A angústia. Rio de Janeiro: Jorge Zahar.

(1964/1975) Le Séminaire Livre XI, Les quatres concepts fondamentaux pour la psychanalyse. Paris: Seuil.

(1967-1968/1986) Seminário Libro 15, El acto psicoanalítico. Buenos

Aires: Paidós, CD-ROM.

(1972-1973/1975) Le Séminaire Livre XX, Encore. Paris: Seuil.

(1973). Télévision. Paris: Seuil.

MELMAN, C. (2003) O homem sem gravidade, gozar a qualquer preço. Rio de Janeiro: Companhia de Freud.

MILLER, J.A. (1993) Infortunios del acto analitico. Buenos Aires: Atuel.

NARDI, A.E. e VALENÇA A. M. (2005) Transtorno do pânico: diagnóstico e tratamento. Rio de Janeiro: Guanabara Koogan.

NOGUEIRA, C.S.P. (2006) "A questão do pai para o adolescente infrator e os impasses na transmissão do desejo”. Dissertação de Mestrado, Programa de Pós-Graduação em Psicologia, Faculdade de Filosofia e Ciências Humanas, Universidade Federal de Minas Gerais

PINTO, J. (2006) "Psicanálise e universidade: mais, ainda", in LO BIANCO, A.C. (Org.) Freud não explica: a psicanálise nas universidades. Rio de Janeiro: Contra-Capa.

PINTO, J. (2008) Psicanálise, feminino, singular. Belo Horizonte: Autêntica.

RECALCATI, M. (2001) Os dois nada da anorexia. Correio, n.32, Belo Horizonte, p.26-36. 
VARELLA, D. (2005) Depressão. Disponível em:<http://www.drauziovarella.com.br/artigos/depressao.asp.> Acesso em 23/5/2010.

VIDAL, E. (1993) Passagem ao ato e acting out. Letra Freudiana, ano 12, n.1-4, Rio de Janeiro, p.211-221.

WAJCMAN, G. (1998) L’objet du siècle. Paris: Verdier.

ZANOTI, S.V. (2006) "Os jovens e o agir: respostas ao mal-estar". Tese de Doutorado, Programa de Pós-Graduação em Teoria Psicanalítica, Instituto de Psicologia, Universidade Federal do Rio de Janeiro.

\author{
Cristina Moreira Marcos \\ cristinammarcos@gmail.com \\ Carla de Abreu Machado Derzi \\ carladerzi@mail.com
}

